\title{
The effect of informal communication on the leadership styles in governmental organizations
}

\author{
Saeed Sehhat ${ }^{a}$, Mehdi Jafarzadeh Kenari*a ${ }^{* a}$ and Mehdi Alipour ${ }^{b}$
}

${ }^{a}$ Department of Management and Accounting, Allame Tabtabaee University, Tehran, Iran

${ }^{b}$ Department of Management, Shahed University, Tehran, Iran

\begin{tabular}{|c|c|}
\hline A R T I C L E I N F O & A B S T R A C T \\
\hline $\begin{array}{l}\text { Article history: } \\
\text { Received March 29, } 2012 \\
\text { Received in Revised form } \\
\text { June, 12, } 2012 \\
\text { Accepted } 19 \text { June } 2012 \\
\text { Available online } \\
\text { June 28 } 2012 \\
\text { Keywords: } \\
\text { Leadership style } \\
\text { Informal relationship } \\
\text { Task-oriented leadership } \\
\text { Relationship-oriented leadership }\end{array}$ & $\begin{array}{l}\text { These days, it is not possible to accomplish tasks without having productive relationships with } \\
\text { the rest of the world. Although there are some evidences, which indicate informal organizations } \\
\text { normally face some limitations on their return but there are also some studies suggesting that } \\
\text { informal organizations are the best ways for making significant changes. Recently, many people } \\
\text { have suggested that informal organizations provide good infrastructures for organization's } \\
\text { workflow many conflict of interests could be solved using informal communications. News can } \\
\text { be distributed in organizations through informal units much easier and it is easier to handle } \\
\text { them. In this paper, we investigate the relationship between informal communications with } \\
\text { leadership style in some of governmental organizations located in free islands of Chabahar, in } \\
\text { south east part of Iran. The proposed model of this paper designs a questionnaire and distributes } \\
\text { it among many people who are acting as managers in those firms. The preliminary results } \\
\text { indicate that there is a positive and meaningful relationship between leadership style and } \\
\text { informal relationships. }\end{array}$ \\
\hline
\end{tabular}

(C) 2012 Growing Science Ltd. All rights reserved.

\section{Introduction}

Leadership style plays an important role on managing an organization, an appropriate leadership can increase business units' performance, increases profitability and create better environment to work. During the past few years, there were growing interests on leadership style and its effects on organizations.

Jahromi et al. (2011) performed an empirical investigation to study of the relationship between dominant brain hemispheres with leadership styles, task oriented and relation oriented (integrated) among active managers of Shiraz University of medical sciences. They used a sample including 72 active senior and junior managers of Shiraz University of medical sciences and the whole statistical population was investigated. In their study, they used two kinds of questionnaires: Questionnaire for

\footnotetext{
* Corresponding author. Tel: +989362647628

E-mail addresses: m.j.kenari@gmail.com (M. Jafarzadeh Kenari) 
dominant brain hemisphere and questionnaire for leadership style and based on the results they claimed that there was no substantial relationship between dominant brain hemisphere and leadership style on task related style. They also reported no significant relationship between dominant brain hemisphere and manager seniority.

There are many evidences to believe that by developing strong organizational culture and effective leadership, corporations can reach better business performance. Zehir et al. (2011) tried to fill the gap in the literature by investigating the relationship between the leadership, culture and performance using the data collected from national and global firms in various sectors including manufacturing, finance and telecommunication in Turkey. The survey was performed on 295 employees who accepted to respond to the questionnaires. They performed regression analyses for testing the hypotheses and their results were consistent with literature.

Battilana et al. (2010) reported that that treating planned organizational change as a generic feature might cover important idiosyncrasies associated both with the various activities involved in the change implementation process and with the unique functions, which leadership competencies might play in the execution of these activities.

Shondrick et al. (2010) performed a review on key findings related to leadership categorization theory and developed some new perspectives regarding the design of behavioral measures of leadership. They also discussed the implications of shared and complex adaptive leadership conceptualizations of leadership. More specifically, by applying recent developments in cognitive science, they discussed how an understanding of connectionist, symbolic, and embodied representations of knowledge could take advantage of behavioral measures of leadership. They also discussed some practical issues related to the measurement of leadership and argued that ratings which tap episodic memory at the event level could be more meaningful than ratings based on semantic memory. They also discussed how notions of shared leadership and of leaders as catalysts for complexity could create unique complications for leadership perceptions, coordinated behavior within a group, and the measurement of leadership.

Özsahin et al. (2011) investigated the crises in Turkey in 1994, 1999 and 2001 and studied some firms that managed the crises to survive and they have become high performing organizations of Turkey. The high performing organization survived in crises has absorbed much attention of so different researchers and characteristics of those firms began to be surveyed. Özsahin et al. (2011) examined and revealed the characteristics of those high performing firms and explained that leadership is subject to so many studies examining the high performing organizations in literature. There are also other issues such as leadership style, cultural competitiveness emphasized as another high performing factors. Within the framework of cultural competitiveness, the study concentrated on the notion that learning orientation as one of the cultural based elements, which influence firm performance mediated the relationship between leadership style and firma performance. They also reported that both dimensions of learning orientation including commitment to learning and shared vision and open-mindedness could mediate the impacts of the relations-oriented and task-oriented leadership on the firm performance.

\section{The proposed model}

In this paper, we study the correlation ratio among different variables. The proposed study of this paper designs a questionnaire and distributes it among different people. As we explained earlier, we investigate the relationship between informal communications with leadership style in some of governmental organizations located in free islands of Chabahar, in southeast part of Iran. The proposed model of this paper designs a questionnaire and distributes it among many people who are 
acting as managers in those firms. We have used a simple random sampling technique and considered the information of 60 people. In terms of gender, 11 people were female $(18.3 \%)$ and 49 people or $81.7 \%$ were male. Table 1 shows some of descriptive information of the people who participated in our survey.

Table 1

Characteristics of the participants in terms of their age

\begin{tabular}{ccccc}
\hline Age & Frequency & Percentage & Valid percentage & Accumulative \\
\hline $20-30$ & 26 & 43.3 & 43.3 & 43.3 \\
$30-40$ & 17 & 28.3 & 28.3 & 71.7 \\
$40-50$ & 14 & 23.3 & 23.3 & 95.0 \\
$>50$ & 3 & 5.0 & 5.0 & 100.0 \\
\hline Total & 60 & 100.0 & 100.0 & \\
\hline
\end{tabular}

Table 2 shows details of the participants in terms of their educational backgrounds. As we can observe from the results of Table 2, a big portion of the people who took part in our survey maintained at least bachelor degrees of science.

Table 2

Educational backgrounds of participants

\begin{tabular}{ccccc}
\hline Years of educations & Frequency & Percentage & Valid Percentage & Accumulated \\
\hline$<=12$ & 1 & 1.7 & 1.7 & 1.7 \\
14 & 22 & 36.7 & 36.7 & 38.3 \\
16 & 33 & 55.0 & 55.0 & 93.3 \\
$>=16$ & 4 & 6.7 & 6.7 & 100.0 \\
\hline Total & 60 & 100.0 & 100.0 & \\
\hline
\end{tabular}

We first distributed the questionnaire among five managers and the data was validated. Cronbach alpha were calculated as 0.928 and 0.935 for leadership style and relationship ability, respectively, which are well above the minimum acceptable level of 0.70 and this validates the questionnaire. There were 20 questions for task-oriented leadership style, 15 questions for relationship-oriented leadership style, 35 questions for leadership scale and 30 questions for communication styles and Cronbach alphas were calculated as $0.925,0.804,0.928$ and 0.935 , respectively.

\subsection{Research hypotheses}

The main hypothesis of this paper is as follows,

There is a meaningful relationship between leadership style and informal relationships.

There are also two sub-hypotheses associated with the proposed study of this paper as follows,

1. There is a meaningful relationship between relationship-oriented leadership and informal relationships.

2. There is a meaningful relationship between task-oriented leadership and informal relationships.

In order to test all hypotheses, the null hypothesis is considered as the Pearson correlation ratio becomes zero $(r=0)$ and the null hypothesis was that the Pearson correlation ratio is not equal to 
zero $(r \neq 0)$ (Soper et al., 1917; Rodgers \& Nicewander, 1988). The level of significance is considered as 0.05 and the mean of responses for all questions are considered to test the hypothesis.

\section{The results}

In this section, we present details of testing different hypotheses explained in the previous section. The first hypothesis is associated with the relationship between leadership style and informal relationships. Table 3 shows details of our findings about mean, standard deviation and sample sizes of informal and leadership style.

\section{Table 3}

Mean, standard deviation and sample size

\begin{tabular}{cccc}
\hline & mean & Standard deviation & Sample size \\
\hline Informal relationships & 78.8000 & 16.10222 & 60 \\
Leadership style & 111.4000 & 22.35552 & 60 \\
\hline
\end{tabular}

Table 4 shows details of our finding on Pearson correlation test. The Pearson ratio for this test was calculated as -0.652 . Therefore, we can reject the null hypothesis and conclude that as the level of leadership increases (task or relationship oriented) the level of informal relationship among managers will be reduced.

\section{Table 4}

Pearson correlation test results between leadership style and information relationships

\begin{tabular}{lcc}
\hline & Informal relationship & Leadership style \\
\hline Pearson correlation test & 1 & $-0 \cdot 652$ \\
two sides Sig & & 0.000 \\
Pearson correlation test & $-0 \cdot 652$ & 1 \\
two sides Sig & 0.000 & 60 \\
Sample size & 60 & 60 \\
\hline
\end{tabular}

\subsection{The relations between relationship-oriented leadership style and informal relationship}

The first sub-hypothesis is associated with the relationship between leadership style and informal communication among managers. Table 5 shows details of our findings on this test.

\section{Table 5}

Pearson correlation test results between relationship-oriented leadership style and information relationships

\begin{tabular}{lcc}
\hline & Informal relationship & relationship-oriented leadership style \\
\hline Pearson correlation test & 1 & $-0 \cdot 364$ \\
two sides Sig & & 0.000 \\
Pearson correlation test & $-0 \cdot 364$ & 1 \\
two sides Sig & 0.004 & 60 \\
Sample size & 60 & \\
\hline
\end{tabular}

As we can observe from the results of Table 5, there is a negative relationship between two variables and Pearson correlation test is calculated as -0.364 , which means as the leadership style increases we can expect less relationship-oriented relationships. 


\subsection{The relations between task-oriented leadership style and informal relationship}

The first sub-hypothesis is associated with the relationship between leadership style and informal communication among managers. Table 6 shows details of our findings on this test.

\section{Table 6}

Pearson correlation test results between task-oriented leadership style and information relationships

\begin{tabular}{lcc}
\hline & Informal relationship & Task-oriented leadership style \\
\hline Pearson correlation test & 1 & $-0 \cdot 733$ \\
two sides Sig & & 0.000 \\
Pearson correlation test & $-0 \cdot 733$ & 1 \\
two sides Sig & 0.004 & 60 \\
Sample size & 60 & \\
\hline
\end{tabular}

As we can observe from the results of Table 6, there is a negative relationship between two variables and Pearson correlation test is calculated as -0.733 , which means as the leadership style increases we can expect less task-oriented relationships.

In summary, we can conclude that the main hypothesis and the other two sub-hypotheses have been confirmed and Table 7 shows details of our findings.

Table 7

The results of testing different hypothesis

\begin{tabular}{lccc}
\hline Hypothesis & Pearson ratio & Sig & Result \\
\hline $\begin{array}{l}\text { Relationship between leadership style and informal } \\
\text { relationships }\end{array}$ & -0.652 & 0.000 & Confirmed \\
\hline $\begin{array}{l}\text { Relationship between relationship-oriented } \\
\text { leadership style and informal relationships }\end{array}$ & -0.364 & 0.004 & Confirmed \\
$\begin{array}{l}\text { Relationship between task-oriented leadership style } \\
\text { and informal relationships }\end{array}$ & -0.733 & 0.000 & Confirmed \\
\hline
\end{tabular}

\section{Conclusion}

The main purpose of this paper was to study the effect of leadership style on informal relationship in organization. The results of our survey has indicated that there is an indeed a negative relationship between these two factors. In other words, as the leadership style increases there is less informal relationship among managers. Note that communication and having a good informal relationship play important roles on increasing efficiency of an organization and in case, there is an escalation on leadership style, we need to use other techniques to maintain informal relationships among managers. For instance, management could use relationship-oriented leadership style first and then uses taskoriented leadership. Management could use leadership style according to the maturity level of employees in order to reduce the disadvantages of informal communication. It is also possible to use a hybrid of these two methods and assign more responsibility to employees. Management team needs to spend more time to meet their colleagues in informal meetings trying to have a better understanding on existing formal and informal relationships among management team.

\section{Acknowledgment}

The authors would like to thank Mr Alireza Bakhshizadeh for providing assistance on this research work. 


\section{References}

Battilana, J., Gilmartin, M., Sengul, M., Pache, A.C., \& Alexander, J.A. (2010). Leadership competencies for implementing planned organizational change. The Leadership Quarterly, 21(3), 422-438

Jahromi, S.A.S., Gholtash, A., \& Saeedian, M. (2011). A study of the relationship between dominant brain hemispheres with leadership styles, task oriented and relation oriented (integrated) among active managers of Shiraz University of medical sciences. Procedia - Social and Behavioral Sciences, 15, 633-636.

Özsahin, M., Zehir, C., Acar, A.Z. (2011). Linking leadership style to firm performance: the mediating effect of the learning orientation. Procedia - Social and Behavioral Sciences, 24, 15461559.

Rodgers, J.L., \& Nicewander, W.L. (1988). Thirteen ways to look at the correlation coefficient. The American Statistician, 42(1), 59-66.

Shondrick, S.J., Dinh, J.E., \& Lord, R.G. (2010). Developments in implicit leadership theory and cognitive science: Applications to improving measurement and understanding alternatives to hierarchical leadership. The Leadership Quarterly, 21(6), 959-978.

Soper, H.E., Young, A.W., Cave, B.M., Lee, A., Pearson, K. (1917). On the distribution of the correlation coefficient in small samples. Appendix II to the papers of "Student" and R. A. Fisher. A co-operative study, Biometrika, 11, 328-413.

Zehir, C. Ertosun, Ö. G., Zehir, S. \& Müceldili, B. (2011). The Effects of Leadership Styles and Organizational Culture over Firm Performance: Multi-National Companies in İstanbul. Procedia Social and Behavioral Sciences, 24, 1460-1474. 